\title{
Plasmodium Falciparum Malaria
}

\author{
AN AMELANOTIC MELANOMA CELL LINE BEARS RECEPTORS FOR THE \\ KNOB LIGAND ON INFECTED ERYTHROCYTES
}

\author{
John A. Schmidt, Iroka J. Udeinya, James H. Leech, Robert J. Hay, \\ Masamichi Aikawa, John Barnwell, Ira Green, and Louis H. Miller, \\ Laboratory of Immunology and Laboratory of Parasitic Diseases, National \\ Institute of Allergy and Infectious Diseases, National Institutes of Health, \\ Bethesda, Maryland 20205; The American Type Culture Collection, Rockville, \\ Maryland 20852; and the Institute of Pathology, Case Western Reserve \\ University, Cleveland, Ohio 44106
}

A B S T RACT Erythrocytes infected with Plasmodium falciparum trophozoites and schizonts are not seen in the peripheral circulation because they attach to venular endothelium via knoblike structures on the infected erythrocyte membrane. We have recently shown that erythrocytes containing $P$. falciparum trophozoites and schizonts likewise attach to cultured human venous endothelial cells via knobs. In search of a more practical target cell for large scale binding studies designed to characterize and isolate the knob ligand, we tested various normal cells and continuous cell lines for their ability to bind $P$. falciparum-infected erythrocytes. Of the 18 cell types tested, binding of infected erythrocytes was observed to a human amelanotic melanoma cell line and amnion epithelial cells as well as to human aortic and umbilical vein endothelial cells. 96-100\% of amelanotic melanoma cells bound $17 \pm 4$ ( \pm 1 SEM) infected erythrocytes per positive cell, whereas fewer endothelial cells (4-59\%) and amnion epithelial cells $(8-19 \%)$ were capable of binding $12 \pm 5$ and $4 \pm 1$ infected erythrocytes per positive cell, respectively. Further studies designed to compare the mechanism of binding to the amelanotic melanoma cell line and endothelial cells showed the following results. First, that adhesion of infected erythrocytes to these two cell types was parasite stagespecific in that only erythrocytes containing late ring forms, trophozoites, and schizonts bound. Erythrocytes containing early ring forms, which do not attach to venular endothelium in vivo, did not bind to either

Received for publication 20 November 1981 and in revised form 13 April 1982. cell type. Second, erythrocytes infected with trophozoites and schizonts of $P$. vivax or a knobless strain of $P$. falciparum, both of which continue to circulate in vivo, did not bind to either target cell type. Third, transmission electron microscopy showed that infected erythrocytes attached to the amelanotic melanoma cells via knobs. We conclude that cultured human endothelial cells and an amelanotic melanoma cell line share common determinants on their surface and that the mechanism of binding to these two different cell types is similar. The amelanotic melanoma cell line offers a useful substitute for endothelial cells in binding studies requiring large numbers of target cells.

\section{INTRODUCTION}

Of the four species of Plasmodium causing human malaria, $P$. falciparum causes the most morbidity and mortality and is most likely to be chloroquine resistant. The clinical manifestations of the disease are caused by erythrocytic parasites that consist of a series of developmental stages known as rings, trophozoites, and schizonts. In $\boldsymbol{P}$. falciparum malaria, erythrocytes containing trophozoites and schizonts are absent from the circulation because they attach to venular endothelium via electron-dense structures on the infected erythrocyte membrane known as knobs (1). This phenomenon is called sequestration. The sequestered mature parasites evade destruction in the spleen, and are thus able to release merozoites that invade uninfected erythrocytes and initiate additional cycles of asexual development. In addition, the adhesion of erythrocytes containing $\boldsymbol{P}$. falciparum trophozoites and schizonts to venular endothelium may impede the flow of blood 
and therefore play an important role in the pathogenesis of cerebral malaria.

To facilitate studies of the molecular mechanism of sequestration and its role in the pathogenesis of $P$. falciparum malaria, we recently developed an in vitro binding assay using cultured human endothelial cells from umbilical vein (2). In this assay system binding of $P$. falciparum-infected erythrocytes to cultured endothelial cells via knobs was observed. For a number of reasons, freshly obtained endothelial cells proved unwieldy for large scale binding studies and we therefore tested a variety of other cell types for their ability to bind malaria-infected erythrocytes. One of these, a line of amelanotic melanoma cells, binds large numbers of infected erythrocytes. By a number of criteria, the mechanism of binding to amelanotic melanoma cells and endothelial cells is similar. Thus, amelanotic melanoma cells, which grow rapidly in culture, offer a practical alternative to endothelial cells for largescale in vitro studies designed to characterize and isolate the knob ligand on infected erythrocytes.

\section{METHODS}

Malaria-infected erythrocytes. Erythrocytes infected with the knob positive, sequestering Malayan Camp/CHQ strain of $\boldsymbol{P}$. falciparum were obtained at the ring stage from an Aotus trivirgatus grisiemembra monkey, cryopreserved (3), and later used for all of the experiments in this study unless stated otherwise. Erythrocytes infected with a knobless, nonsequestering variant of a St. Lucia strain of $P$. falciparum originally acquired from Dr. William Collins (Center for Disease Control, Atlanta, GA) were likewise obtained at the ring stage from an Aotus trivirgatus grisiemembra monkey and cryopreserved. Aliquots were thawed as needed and cultured for 28-30 h until the rings had matured into trophozoites and schizonts (4). In those experiments that investigated the parasite stage specificity of binding, the thawed infected erythrocytes were further synchronized at the ring stage by incubating at a $10 \%$ hematocrit in $5 \%$ sorbitol for $10 \mathrm{~min}$ at $37^{\circ} \mathrm{C}$ before initiating culture (5).

A Brazilian strain of $\boldsymbol{P}$. falciparum (It) kindly provided by Dr. M. McNeil (Walter Reed Army Institute of Research, Washington, DC) was cultured continuously in human erythrocytes (4) and was also tested for binding.

Erythrocytes infected with $P$. vivax (Salvador I) were kindly provided by Dr. Robert Gwadz (Malaria Section, Laboratory of Parasitic Diseases, National Institutes of Allergy and Infectious Diseases, National Institutes of Health) and were obtained by bleeding an infected Aotus trivirgatus trivirgatus monkey immediately before assay for binding. After the addition of ADP, the blood was passed over glass beads to remove leukocytes and agglutinated platelets. To concentrate the erythrocytes containing trophozoites and schizonts, the blood was then spun in microhematocrit tubes, which resulted in the formation of a parasite-enriched brown layer above the uninfected erythrocytes. Erythrocyte suspensions containing 3-5\% trophozoites and schizonts were obtained by breaking the tubes beneath the brown zone and washing out the cells with medium.

Culture of vascular cells. Venous endothelial cells were obtained from human umbilical vein (6). The umbilical vein endothelial cells used for the majority of these studies were cultured as previously described (6). In a few experiments they were grown on biological substrates (generated by bovine corneal endothelial cells) with or without the addition of fibroblast growth factor, a generous gift from Dr. Denis Gospodarowicz (University of California, San Francisco), as previously described (7). Human aortic endothelial cells were obtained from post mortem specimens kindly provided by Dr. Moon Shin [University of Maryland Medical Center, Baltimore, MD]. The endothelium was gently scraped with the edge of a sterile glass slide and the tissue fragments were cultured as previously described (6). The cultures used for these studies consisted exclusively of endothelial cells as demonstrated by Factor VIII staining (8) and typical cobblestone morphology.

Vascular smooth muscle cells were obtained by mincing the previously scraped aorta (see above) and suspending the tissue fragments in phosphate-buffered saline containing 0.5 $\mathrm{mg} / \mathrm{ml}$ trypsin and $0.2 \mathrm{mg} / \mathrm{ml}$ EDTA for $30 \mathrm{~min}$ at $37^{\circ} \mathrm{C}$ with gentle stirring. The released cells were spun $(1,400 \mathrm{rpm}$, $10 \mathrm{~min}$ ), resuspended in culture medium, and cultured as previously described (6). The cultures consisted of a morphologically homogeneous population of spindle-shaped cells. Electron microscopy kindly performed by Dr. Victor Ferrans (National Heart, Lung, and Blood Institute, NIH) confirmed that the cells were smooth muscle cells.

Bovine aortic endothelial cells were generously provided by Dr. Silja Seppa (National Institute of Dental Research, NIH, Bethesda, MD) and cultured as previously described (9).

Amnion epithelial cells. Amnion epithelial cells were freshly obtained by dissociation of amniotic membranes stripped from term human placenta and cultured as previously described (10).

Cell lines. The cell lines used were obtained from the American Type Culture Collection (ATCC) [Table I]. The cells were inoculated at a density of $1-7 \times 10^{6} / 25 \mathrm{~cm}^{2}$ in the media indicated and assayed 1-5 d later for binding.

Binding assay. The various culture media were aspirated from the target cells and replaced with $0.5-1.5 \mathrm{ml}$ of a $1.0 \%$ suspension of infected erythrocytes in RPMI 1640 medium containing $15 \%$ human AB serum. Only $1-4 \%$ of the erythrocytes in these suspensions were parasitized with trophozoites and schizonts. The cell mixtures were then transferred to a humidified incubator $\left(10 \% \mathrm{CO}_{2} /\right.$ air $)$ and rocked gently by hand every $15 \mathrm{~min}$. After $90 \mathrm{~min}$ the adherent cells were washed free of nonadherent cells, fixed, and stained as previously described (2).

Electronmicroscopy. Samples to be examined by transmission electron microscopy were fixed in $2 \%$ gluteraldehyde/0.1 M cacodylate buffer ( $\mathrm{pH} 7.3$ ) containing $4 \%$ sucrose. After fixation, the sample was dehydrated in ethanol and embedded in Spurr (Polysciences, Inc., Warrington, PA). Thin sections were stained with uranyl acetate and lead citrate and examined with a JEOL 100CX electron microscope (JEOL, Ltd., Tokyo, Japan).

\section{RESULTS}

Binding of malaria infected erythrocytes to different cultured cell types. Aotus erythrocytes infected with trophozoites and schizonts of the sequestering, knob-positive Malayan Camp/CHQ strain of $P$. falciparum were used to screen various normal cells and continuous cell lines (Table I) for their ability to bind $P$. falciparum-infected erythrocytes. Of the nor- 
TABLE I

Cultured Cells Used to Test for Binding of P. falciparum [Malayan Camp/CHQfInfected Aotus Erythrocytes

\begin{tabular}{|c|c|c|c|}
\hline \multicolumn{4}{|c|}{ Normal cells } \\
\hline \multicolumn{3}{|c|}{ Cell type } & Medium used \\
\hline \multicolumn{3}{|c|}{$\begin{array}{l}\text { Human endothelial cells from } \\
\text { umbilical vein } \\
\text { adult aorta } \\
\text { Human aortic smooth muscle cells } \\
\text { Bovine aortic endothelial cells } \\
\text { Human amnion epithelial cells }\end{array}$} & $\begin{array}{l}\text { Medium 199-20 Hu } \\
\text { Medium 199-20 Hu } \\
\text { Medium 199-20 Hu } \\
\text { DMEM-10F } \\
\text { ENEM-10F }\end{array}$ \\
\hline \multicolumn{4}{|c|}{ Continuous cell lines from the ATCC } \\
\hline CCL 2 & HeLa & Human cervical epithelioid carcinoma & CRCM-10F \\
\hline CCL 75 & WI38 & Human lung fibroblasts & EMEM-10F \\
\hline CCL 98 & BeWo & Human choriocarcinoma & F12K-10F \\
\hline CCL 107 & C6 & Rat glial tumor & CRCM-15H/2.5F \\
\hline CCL 185 & A549 & Human lung carcinoma & F12K-10F \\
\hline CCL 218 & WiDr & Human colonic adenocarcinoma & EMEM-10F \\
\hline CCL 229 & LoVo & Human colonic adenocarcinoma & F12K-10F \\
\hline CCL 230 & SW403 & Human colonic adenocarcinoma & L15-10F \\
\hline CCL 239 & WCMC & Human colon mucosal cells & EMEM-25F \\
\hline CRL 1583 & 3A Pre & SV-40 transformed human trophoblasts & EMEM-10F \\
\hline CRL 1584 & 3A Post & SV -40 transformed human trophoblasts & EMEM-10F \\
\hline CRL 1585 & $\mathrm{C} 32 \mathrm{r}$ & Human amelanotic melanoma & EMEM-10F \\
\hline CRL 1424 & G361 & Human melanin-producing malignant melanoma & DMEM-10F \\
\hline
\end{tabular}

- For more information on these cell lines and media see ATCC catalogue of strains II. The suffix numbers after medium used indicate concentrations of fetal bovine serum $(F)$, horse serum $(H)$, or human $A B$ serum $(\mathrm{Hu})$ used.

TABLE II

Attachment of P. falciparum [Malayan Camp/CHQ\}-Infected Aotus Erythrocytes to Human Endothelial Cells, Amelanotic Melanoma Cells, and Amnion Epithelial Cells ${ }^{\bullet}$

\begin{tabular}{|c|c|c|c|}
\hline & $\begin{array}{c}\text { Mean percent } \\
\text { target cells binding } \\
\text { infected erythrocytes }\end{array}$ & $\begin{array}{l}\text { Mean number of } \\
\text { infected erythrocytes per } \\
\text { positive target cell }\end{array}$ & $\begin{array}{l}\text { Mean number of } \\
\text { infected erythrocytes per } \\
100 \text { target cells }\end{array}$ \\
\hline Endothelial cells $\ddagger$ & $\begin{array}{c}27 \pm 9 \\
(4-59)\end{array}$ & $\begin{array}{l}12 \pm 5 \\
(5-34)\end{array}$ & $\begin{array}{l}225 \pm 119 \\
(36-826)\end{array}$ \\
\hline Melanoma cells $\S$ & $\begin{array}{c}99 \pm 1 \\
(96-100)\end{array}$ & $\begin{array}{c}17 \pm 4 \\
(8-26)\end{array}$ & $\begin{array}{c}1,669 \pm 379 \\
(768-2,600)\end{array}$ \\
\hline Amnion cells§̧ & $\begin{array}{c}11 \pm 3 \\
(8-19)\end{array}$ & $\begin{array}{c}4 \pm 1 \\
(2-5)\end{array}$ & $\begin{array}{r}44 \pm 18 \\
(16-95)\end{array}$ \\
\hline
\end{tabular}

- Single experiments were performed on different days using aliquots from the same lot of cryopreserved infected erythrocytes. A minimum of 200 target cells were counted per experiment. A positive cell was defined as one having one or more infected erythrocytes attached to its surface. The data are given as the mean \pm 1 SEM. The range is shown in parentheses. f Six experiments were performed with human endothelial cells consisting of four experiments with umbilical vein endothelial cells from several different individuals and two experiments with adult aortic endothelial cells from two different individuals. Since the results obtained with the two types of human endothelial cells were comparable, the data were pooled.

$\$$ The data are the results of four experiments.

"Amnion epithelial cells from two amniotic membranes were used for these studies. 


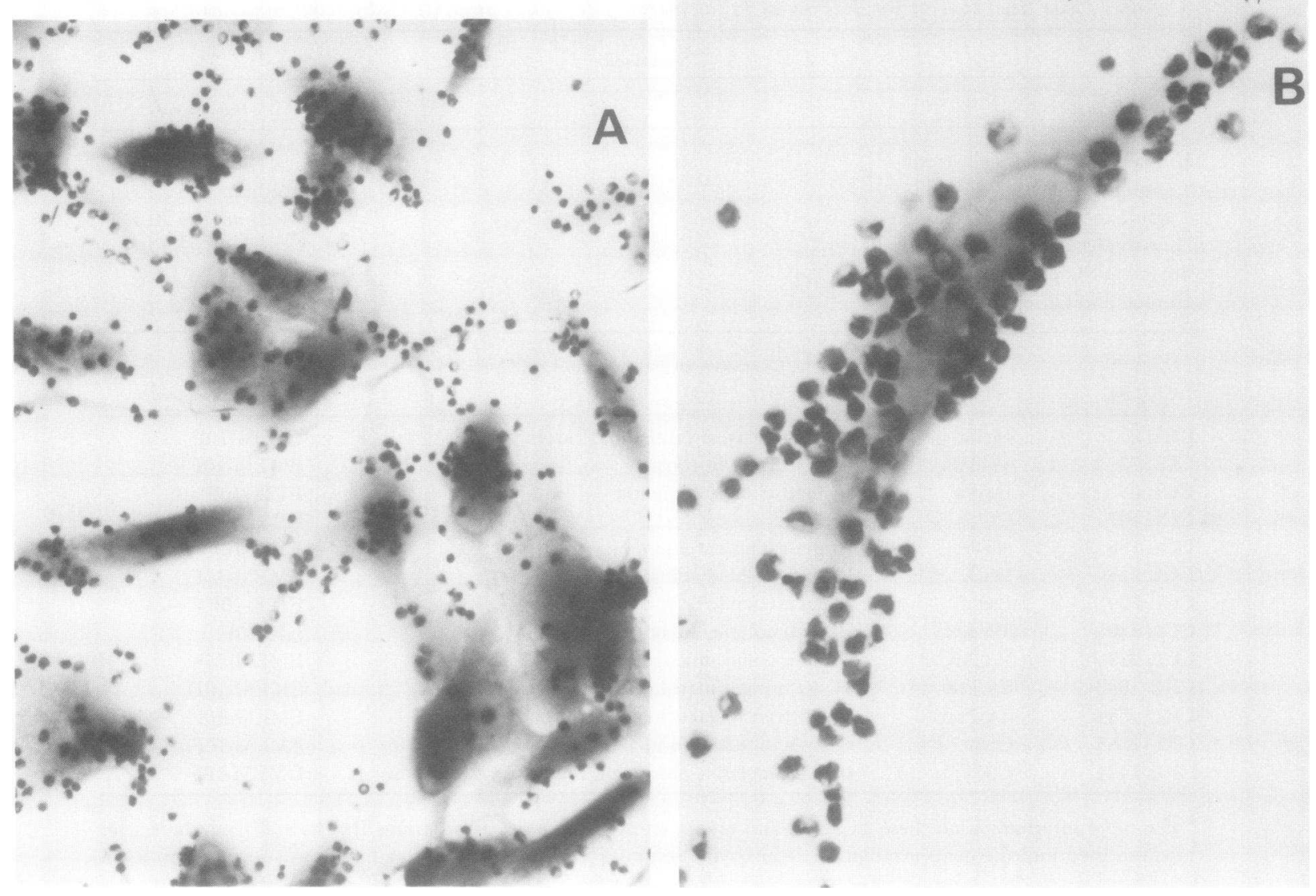

Figure 1 A, B. Light micrographs of $P$. falciparum [Malayan Camp/CHQ] infected erythrocytes attached to human amelanotic melanoma cells $(\times 330, \mathrm{~A} ; \times 860, \mathrm{~B})$. All of the bound erythrocytes contain either trophozoites or schizonts. C. Electron micrograph $(\times 34,000)$ showing an Aotus erythrocyte (E) containing a mature $P$. falciparum schizont with four merozoites (Mz) attached to the surface of an amelanotic melanoma cell (Me) by knoblike protrusions on the infected erythrocyte membrane (arrows).

mal cells tested, human umbilical vein and aortic endothelial cells cultured as previously described (6) bound infected erythrocytes (Table II). Human umbilical vein endothelial cells grown on biological substrates with or without the addition of fibroblast growth factor (7) grew rapidly, but in general, bound infected erythrocytes less well than endothelial cells grown using more conventional tissue culture techniques (6) (data not shown). Human amnion epithelial cells also bound infected erythrocytes (Table II). Infected erythrocytes were not bound by human vascular smooth muscle cells and bovine aortic endothelial cells. Of the various continuous cell lines tested, only an amelanotic melanoma cell line (ATCC No. CRL 1585) bound infected erythrocytes (Fig. 1A, B; Table II). Another human melanoma line (CRL 1424) did not bind infected erythrocytes. The amnion epithelial cells and amelanotic melanoma cells did not contain Factor VIII antigen, an endothelial cell marker (8), as determined by immunofluorescent techniques.

In each case, binding was specific for infected erythrocytes, i.e., $>98 \%$ of the bound erythrocytes contained trophozoites or schizonts, whereas $<4 \%$ of the erythrocytes in the starting suspension contained these mature forms. Nearly all (96-100\%) of the amelanotic melanoma cells had infected erythrocytes attached to their surface, whereas a variable percentage of endothelial cells (4-59\%) and amnion epithelial cells (8$19 \%$ ) bound infected erythrocytes (Table II). In addition, the mean number of infected erythrocytes per 100 target cells was much greater for amelanotic melanoma cells than for either endothelial cells or amnion cells (Table II).

Strain and species specificity of malaria-infected 


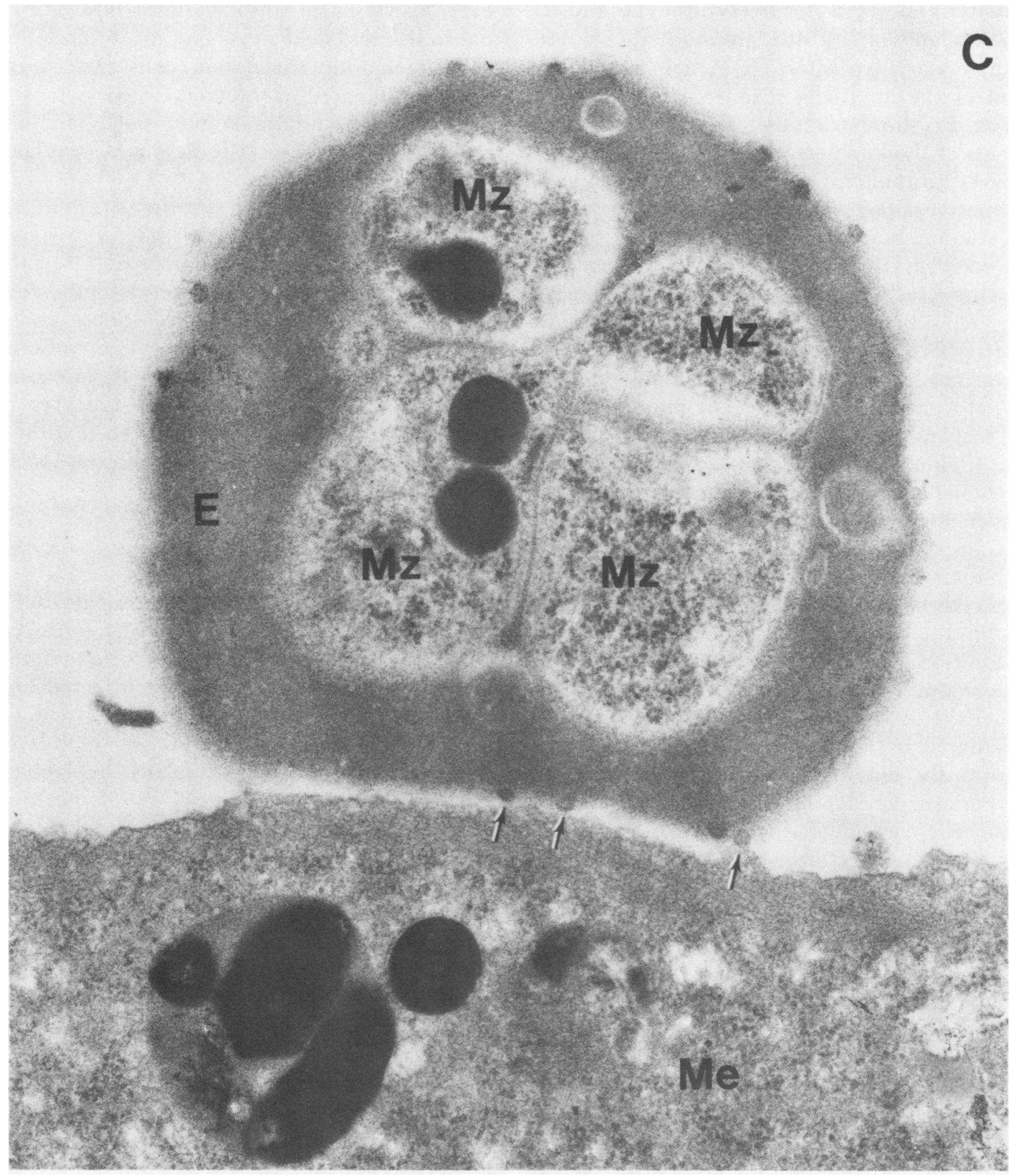

Figure 1 (Continued)

erythrocyte attachment to the amelanotic melanoma cell line and cultured endothelial cells. Having identified a line of amelanotic melanoma cells as potentially useful target cells in binding assays involving a sequestering strain of $P$. falciparum (i.e., Malayan Camp/CHQ), we next studied the ability of this cell line to bind erythrocytes infected with other strains and species of malaria. For comparison, the ability of cultured umbilical vein endothelial cells to bind these various types of malaria-infected erythrocytes was also determined. We first tested the binding of erythrocytes infected with the Brazilian (It) strain of $P$. falciparum. This strain has been cultured continuously in human erythrocytes and induces knobs on the infected cells. Binding to the amelanotic melanoma cell line as well as to endothelial cells was observed (data not shown). As with the Malayan Camp/CHQ strain cultured in Aotus erythrocytes, only trophozoite and schizont-infected erythrocytes were observed to bind.

To further examine the specificity of the interaction 
between malaria infected Aotus erythrocytes and the amelanotic melanoma cell line, we studied two nonsequestering malaria parasites. These included a knobless variant of the St. Lucia strain of $P$. falciparum and $P$. vivax. Erythrocytes infected with trophozoites and schizonts of the knobless variant of $\boldsymbol{P}$. falciparum were observed to remain in the peripheral blood and not to sequester along venular endothelium. Ultrastructural studies showed that no knobs were present on the infected erythrocyte membrane. $P$. vivax-infected erythrocytes are knobless (11) and do not sequester in vivo (12). Erythrocyte suspensions containing 3-5\% trophozoites and schizonts of $P$. vivax or the knobless variant of $P$. falciparum demonstrated no binding whatever to amelanotic melanoma cells. When the same suspensions of infected erythrocytes were assayed for their ability to attach to cultured umbilical vein endothelial cells, no binding was observed. These results, taken together with those obtained with the Malayan Camp/CHQ strain of $P$. falciparum, demonstrate that the amelanotic melanoma cell line and endothelial cells behave similarly when tested for their ability to bind a panel of malaria infected erythrocytes. In addition, the results obtained with the knobless St. Lucia strain suggest that, as in the case of endothelial cells $(1,2)$, binding to amelanotic melanoma cells is mediated by knobs or a knob constitutent(s). Most importantly, binding of malaria infected erythrocytes to both the amelanotic melanoma cell line and endothelial cells correlated directly with the known ability of the infected erythrocytes to sequester in vivo.

Stage specificity of parasitized erythrocyte attachment to the amelanotic melanoma cell line and cultured endothelial cells. Erythrocytes containing early ring forms of $P$. falciparum do not sequester in vivo because they lack the knob ligand found on erythrocytes containing trophozoites and schizonts (1). Although erythrocytes containing ring forms were not observed to bind to cultured endothelial cells or amelanotic melanoma cells in the above experiments, the suspensions of erythrocytes used to test the binding of trophozoites and schizonts might have, after $30 \mathrm{~h}$ of incubation (Methods), contained too few ring forms to adequately evaluate their ability to bind to the target cells. Therefore, to determine if early ring forms bound to cultured endothelial cells and amelanotic melanoma cells, freshly thawed $P$. falciparum [Malayan Camp/CHQ]-infected erythrocytes, which consisted predominantly of ring forms, were incubated in sorbitol to destroy the few trophozoites and schizonts present. The infected erythrocytes were then cultured as usual and assayed periodically for their ability to attach to endothelial cells and amelanotic melanoma cells. As shown in Table III, early rings ( $4 \mathrm{~h}$ after synchronization) did not bind to either cell type. How- ever, as the early rings matured into late rings, trophozoites, and schizonts, binding to endothelial cells and amelanotic melanoma cells rose dramatically. Thus, attachment of infected erythrocytes to both endothelial cells and amelanotic melanoma cells is parasite stage-specific in vitro as it is to venular endothelium in vivo.

Electron microscopic studies of binding to the amelanotic melanoma cell line. Previous electron microscopic studies have shown that $P$. falciparuminfected erythrocytes bind to endothelial cells in vivo (1) and in vitro (2) via electron-dense knoblike protrusions on the infected erythrocyte membrane. Transmission electron microscopy of $P$. falciparum [Malayan Camp/CHQ]-infected erythrocytes bound to amelanotic melanoma cells revealed that the points of attachment were likewise the knobs on the surface of the infected cell (Fig. 1C).

\section{DISCUSSION}

Erythrocytes infected with mature asexual forms of $P$. falciparum are virtually absent from the peripheral circulation because they attach to venular endothelium via knob-like protrusions on the infected erythrocyte membrane (1). Because the isolation and characterization of the knob ligand would be greatly simplified by an in vitro binding assay, we first developed an assay based on the binding of $P$. falciparum-infected erythrocytes to cultured human umbilical vein endothelial cells (2). In the current study, we have found that human aortic endothelial cells also bind infected erythrocytes (Table II). The absence of binding to arterial endothelium in vivo (13) must, therefore, be explained by rheological or other factors. Bovine aortic endothelial cells did not bind infected erythrocytes suggesting that the receptor on endothelial cells is species specific. Finally, another freshly isolated cell type of human vascular origin, smooth muscle cells, did not bind infected erythrocytes.

Although human endothelial cells offer an attractive in vitro system for the further study of knob ligandreceptor interactions (2), their use in large scale binding studies is unwieldy for two reasons: first, it is difficult to grow large numbers of human endothelial cells using conventional tissue culture techniques (7); and second, only a variable percentage of endothelial cells are capable of binding infected erythrocytes during any given assay period (Table II; reference 2). In an attempt to overcome some of these difficulties, we have grown endothelial cells on biological substrates (generated by bovine corneal endothelial cells) with or without the addition of fibroblast growth factor (7). Although these modifications in culture technique led to brisk endothelial cell growth as previously reported 
TABLE III

Stage Specificity of Attachment of P. falciparum [Malayan Camp/CHQ]-Infected Aotus Erythrocytes to Endothelial Cells and Amelanotic Melanoma Cells

\begin{tabular}{|c|c|c|c|c|c|}
\hline \multirow{2}{*}{$\begin{array}{c}\text { Hours post } \\
\text { synchronization }\end{array}$} & \multicolumn{3}{|c|}{ Parasitemia (\%) ${ }^{\bullet}$} & \multicolumn{2}{|c|}{$\begin{array}{l}\text { Mean bound infected erythrocytes } \\
\text { per } 100 \text { target cellst }\end{array}$} \\
\hline & Rings & Trophozoites & Schizonts & Melanoma cells & Endothelial cells \\
\hline 4 & 100 & 0 & 0 & 0 & 1.5 \\
\hline 12 & 100 & 0 & 0 & 45 & 14 \\
\hline 19 & 52 & 48 & $\mathbf{0}$ & 325 & ND\& \\
\hline 24 & 10 & 88 & 2 & 1,860 & 180 \\
\hline 36 & 0 & 29 & 71 & 857 & 228 \\
\hline 49 & 80 & 15 & 5 & 177 & ND \\
\hline
\end{tabular}

- The freshly thawed parasitized erythrocytes were synchronized with sorbitol at the ring stage as described in Methods. The parasites were then allowed to mature in culture and assayed at various times in duplicate for their ability to attach to amelanotic melanoma cells and umbilical vein endothelial cells. Smears of the infected erythrocyte suspension were examined at each time point to determine the percentage of infected erythrocytes containing rings, trophozoites, and schizonts. $\$ 100$ target cells were counted per assay to determine the number of bound infected erythrocytes. An erythrocyte containing any stage of the parasite was considered infected.

$\S$ ND, not done.

(7), the resultant cells performed less well in the binding assay than cells grown without the use of substrates or growth factors.

In search of another cell type for binding studies, we tested a variety of cell types of human and animal origin. Only the amelanotic melanoma cell line and the freshly obtained amnion epithelial cells bound infected erythrocytes. Although amnion epithelial cells can be obtained in large numbers, only a variable percentage of these cells were capable of binding infected erythrocytes and the number of bound erythrocytes per amnion cell was small. In contrast, nearly all of the amelanotic melanoma cells were capable of binding a relatively larger number of infected erythrocytes.

In order for amelanotic melanoma cells to replace endothelial cells in large-scale studies designed to characterize the knob ligand, it is critical that the mechanism of binding be identical. The evidence that the mechanism of binding is very similar is as follows. First, binding to both amelanotic melanoma and endothelial cells is specific in that only infected erythrocytes constituting $<4 \%$ of the starting erythrocyte suspension attach. Second, binding to both amelanotic melanoma cells and endothelial cells is parasite stagespecific in that only erythrocytes containing late rings, trophozoites, and schizonts attach; erythrocytes containing early ring forms do not attach to either target cell type (Table III). These in vitro observations parallel the classical in vivo observation (14), i.e., only young forms are observed in the peripheral blood. The more mature forms have attached to endothelium and are therefore not seen (1). Third, a knobless variant of $P$. falciparum and a nonsequestering species of Plasmodium, $P$. vivax, did not bind to either cell type. Fourth, as in the case of endothelial cells, knobs on infected erythrocytes are the points of attachment between infected erythrocytes and amelanotic melanoma cells.

These observations taken together provide strong evidence that binding of $\boldsymbol{P}$. falciparum-infected erythrocytes to venular endothelium in vivo and to endothelial cells and amelanotic melanoma cells in vitro involves a highly specific interaction between the knobs on the infected erythrocyte membrane and a common target cell determinant. Amelanotic melanoma cells are readily available and easy to grow in culture. They should provide a valuable tool for the characterization and isolation of both the knob ligand on infected erythrocytes as well as the target cell receptor for malaria-infected erythrocytes.

\section{ACKNOWLEDGMENTS}

The authors thank Drs. M. McNeil, Robert Gwadz, and William Collins for malaria-infected erythrocytes; Dr. Moon Shin for tissue specimens; Dr. Silja Seppa for bovine endothelial cells; Dr. Victor Ferrans for electron microscopy of vascular smooth muscle cells; and Dr. Denis Gospodarowicz for helpful suggestions and gift of fibroblast growth factor. We also thank the obstetrical staffs of The National Naval Medical Center, Bethesda, MD and The Holy Cross Hospital, Silver Spring, MD for providing umbilical cords.

This investigation received support from the Malaria Component of the United Nations Development Programme-World Bank-World Health Organization Special Program for Research and Training in Tropical Diseases and the National Institutes of Health AI 10645. 


\section{REFERENCES}

1. Luse, S. A., and L. H. Miller. 1971. Plasmodium falciparum malaria. Ultrastructure of parasitized erythrocytes in cardiac vessels. Am. J. Trop. Med. Hyg. 20: 655-660.

2. Udeinya, I. J., J. A. Schmidt, M. Aikawa, L. H. Miller, and I. Green. 1981. Falciparum malaria-infected erythrocytes specifically bind to cultured human endothelial cells. Science (Wash. DC). 213: 555-557.

3. Diggs, C. L., K. Joseph, B. Flemmings, R. Snodgrass, and $F$. Hines. 1975. Protein synthesis in vitro by cryopreserved Plasmodium falciparum. Am. J. Trop. Med. Hyg. 24: 760-763.

4. Trager, W., and J. B. Jenson. 1976. Human malaria parasites in continuous culture. Science (Wash. DC). 193: 673-675.

5. Lambros, C., and J. P. Vanderberg. 1979. Synchronization of Plasmodium falciparum erythrocytic stages in culture. J. Parasitol. 65: 418-420.

6. Jaffe, E. A., R. L. Nachman, C. G. Becker, and C. R. Minick. 1973. Culture of human endothelial cells derived from umbilical veins. Identification by morphologic and immunologic criteria. J. Clin. Invest. 52: 2745-2756.

7. Gospodarowicz, D., and C. Ill. 1980. Extracellular ma- trix and control of proliferation of vascular endothelial cells. J. Clin. Invest. 65: 1351-1364.

8. Jaffe, E. A., L. W. Hoyer, and R. L. Nachman. 1973. Synthesis of antihemophilic factor antigen by cultured human endothelial cells. J. Clin. Invest. 52: 2757-2764.

9. Glaser, B. M., P. A. D'Amore, H. Seppa, S. Seppa, and E. Schiffman. 1980. Adult tissues contain chemoattractants for endothelial cells. Nature (Lond.). 288: 483-484.

10. Ricard, M. A., and R. J. Hay. 1976. Proliferation and agglutinability of primary and transformed human epithelial cells in culture. J. Cell Sci. 21: 553-561.

11. Aikawa, M., L. H. Miller, and J. Rabbege. 1975. Caveolavesicle complexes in the plasmalemma of erythrocytes infected by Plasmodium vivax and $P$. cynamolgi. Unique structures related to Schuffners dots. Am. J. Pathol. 79: 285-294.

12. Garnham, P. C. 1966. Malaria Parasites and Other Haemosporidia. Blackwell. Scientific Publications, Oxford. p. 128-134.

13. Miller, L. H. 1969. Distribution of mature trophozoites and schizonts of Plasmodium falciparum in the organs of Aotus Trivirgatus, the night monkey. Am. J. Trop. Med. Hyg. 18: 860-865.

14. Bignami, A., and G. Bastianelli. 1889. Observations of Estivo-Autumnal malaria. Riforma Medica. 6: 13341335. 